\title{
The Physiology of Acupuncture Analgesia in Surgery: Considering the Endogenous Opioid Peptides as Major Candidates for roles in Acupuncture's Analgesic Actions
}

\author{
William Cobb* \\ University of Medicine and Health Sciences, West Indies
}

Submission: April 26, 2017; Published: May 05, 2017

*Corresponding author: William Cobb, University of Medicine and Health Sciences, P.O. Box 1218, Basseterre, Saint Kitts, West Indies, Tel: 7452981539; Email: willcobb26@hotmail.co.uk

\begin{abstract}
Acupuncture as a medical treatment in the terms of actual documented practice dates back as far as 305-204 BC. Acupuncture in general therapeutic practice as well as for analgesic purposes has been contested within the medical fraternity for decades, however with recent scientific methods allowing for more detailed analysis of the relationship on the neuromusculoskeletal system and the intricacies of the afferent and efferent pathways of the central nervous system (CNS), the debate has once again come to the forefront of modern medicine. The purpose of this brief mini-review is to look at the physiological perspective of acupuncture and how it has and is being used in modern surgical practice. Is acupuncture purely a placebo manifestation or does it have marked physiological and biochemical actions on the human model and can these indeed be seen?
\end{abstract}

Abbreviations: CSF: Cerebrospinal Fluid; CNS: Central Nervous System; EAA: Electro-Acupuncture Analgesia; EA: Electro-Acupuncture

\section{Introduction}

A brief history of acupuncture: Chinese medical texts document the history and practice of acupuncture in the Classic of Internal Medicine which was compiled around 305-204 BC. This text is the oldest known book on Chinese medicine "Neiching", also known as "The Yellow Emperor's classic of internal medicine". The text itself is in the form of a dialogue between the Yellow Emperor "Huang Ti" and "Chi Po" a Taoist teacher and physician. The historical records believe that the Yellow Emperor lived around 2700 B.C. The Yellow Emperor's classic of internal medicine indicates that acupuncture was widely practised in China much before the time it was written. Historically, acupuncture spread throughout Asia and in 1023 a bronze statue was produced that depicted the meridians and acupuncture points that were in use at the time. The practice of acupuncture became less prestigious and was somewhat beguiled to the practice of shamanism until the period of the mid 1750 s when acupuncture had become somewhat of a lost art.

During this period, the decline was attributed in part to the advent of pharmacotherapy as well as the division of the classes. During the period of 1822, the Chinese Emperor announced that the practice and teaching of acupuncture be banned within the
Imperial Academy of Medicine which continued right up until the ban was lifted in 1950 by Chairman Mao. Mao officially united Traditional Chinese Medicine with Western Medicine which allowed acupuncture to become established in many hospitals. Currently, there are certain hospitals that practice Chinese traditional medicine parallel to that of modern medicine, allowing patients to have a choice of medical interventional options. This is a far more diverse and eclectic dynamic to medicine than the pre-Mao period in which alternative or classical approaches to medicine were somewhat dulled down.

Acupuncture in surgical practice: [1] Professor Oleg Chudakov, MD, DDS, PhD, Faculty of Stomatology, Belarussian State Medical University, Minsk, Belarus presented a study that investigated the use of acupuncture analgesia in maxillofacial surgery. The methodology included using Acupuncture analgesia on 120 patients. In 20 of these, surgery was carried out under general anaesthesia in combination with acupuncture analgesia. In 100 patients, acupuncture analgesia was applied in addition to traditional postoperative analgesia. In the case of troublesome postoperative pain, it was found necessary to carry out additional sessions [1-4] of acupuncture stimulation. 
The results of professor Chudakovs research suggested that when acupuncture analgesia was used, the pulse rate and blood pressure during surgery generally remained stable. During the study serum cortisol was also measured and showed only minor elevation. The study demonstrated favourable results when the first variant of the brake method of acupoint stimulation was used for $40-50 \mathrm{~min}$ with the additional manual twirling of the needles.

This involved inserting needles into the acupoints and, using slow, rolling manual movements increasing the amplitude stepby-step provoking especially strong patient sensations. The paper suggested that Acupuncture analgesia can be a useful adjunct to conventional anaesthesia in maxillofacial surgery. This was also somewhat mimicked in a text by the British Medical Association BMA [2] Acupuncture: Efficacy, Safety and Practice. Which reviewed scores of research looking at the placebo effect of acupuncture and actual needle placement for analgesic responses favouring tested physiological responses over the placebo effect.

The physiology of acupuncture analgesia: The exploration of the physiological mechanism of action of acupuncture started around 1950 during which time a pharmacological study was published at Peking University. The study demonstrated that an induction time of 15 to 20 minutes is required for the development of analgesic effects within acupuncture and more that the involvement of chemical substances in the analgesic manifestations [3]. The pharmaceutical study pointed to the Endogenous Opioid Peptides (EOPs) as major candidates for a role in acupuncture's action, as Electro-Acupuncture Analgesia (EAA) is antagonised by the opioid receptor antagonist naloxone $[4]$.

EAA in human subjects has shown to have incremental effect in EOPs in plasma or cerebrospinal fluid (CSF) following EAA [3]. The Peking University research demonstrated a frequencydependent involvement of different EOPs in electro-acupuncture (EA) induced analgesia. This was accomplished by using varied methodologies to identify the different opioid receptors and their endogenous agonists. Based on several lines of evidence, a conclusion was drawn that low-frequency $(2 \mathrm{~Hz}$ ) EAA is induced by the activation of mu- and delta-opioid receptors via the release of enkephalin, beta-endorphin, and endomorphin in supraspinal CNS regions, whereas the effects of high-frequency $(100 \mathrm{~Hz})$ EAA involve the actions of dynorphin on kappa opioid receptors in the spinal cord [5].

Scope of medical practice: With the advent of more and more breakthroughs in medical imaging and medical sciences in general, the understanding of the involvement of acupuncture in modern medical practice will undoubtedly become more and more evident. This mini review although very brief ponders the further question as to how can science definitively answer the question as to the effectiveness of acupuncture analgesia for surgical intervention, and if indeed future breakthroughs, when combined with traditional medical ideas, may be even more effective. None the less, the post-Mao influence of traditional aetiologies of medical treatment being brought to the forefront of modern medicine undoubtedly gives patients more freedom of choice in treatments, however, this is beyond the scope of this brief review. The biochemical and physiological perspectives of the questions highlighted at the beginning of this review although brief in this circumstance, without a doubt, raise many more questions to the astute scientist as to how, when, where and why modern medicine should or indeed should not merge the ancient theories of medicine, surgery and analgesia.

\section{References}

1. Irina O Pohodenko-Chudakova (2004) Journal of Cranio-Maxillofacial Surgery 33.

2. British Medical Association (BMA) Acupuncture: Efficacy, Safety and Practice: Harwood Academic Publishers, UK.

3. Sjolund B, Terenius L, Ericsson M (1977) Increased cerebrospinal fluid levels of endorphins after electro-acupuncture. Acta Physiol Scand 100: 382-384.

4. Pomeranz B, Chiu D (1976) Naloxone blockade of acupuncture analgesia: endorphin implicated. Life Sci 19: 1757-1762.

5. (1973) Acupuncture Anesthesia. Effect of acupuncture on pain threshold of human skin. Chin Med J 3: 151-158.

\section{Your next submission with Juniper Publishers} will reach you the below assets

- Quality Editorial service

- Swift Peer Review

- Reprints availability

- E-prints Service

- Manuscript Podcast for convenient understanding

- Global attainment for your research

- Manuscript accessibility in different formats ( Pdf, E-pub, Full Text, Audio)

- Unceasing customer service

Track the below URL for one-step submission https://juniperpublishers.com/online-submission.php 